Aimee Caroline E. Lim, MD' Melfred L. Hernandez, MD, MHA ${ }^{1}$

Erasmo Gonzalo DV, Llanes, MD ${ }^{1,2}$

'Department of Otorhinolaryngology

Philippine General Hospital

University of the Philippines Manila

2Philippine National Ear Institute

National Institutes of Health

University of the Philippines Manila

Correspondence: Aimee Caroline E. Lim, MD

Department of Otorhinolaryngology

Ward 10, Philippine General Hospital

Taft Avenue, Ermita, Manila 1000

Philippines

Phone: (632) 5264360

Fax: (632) 5255444

Email: aimeecarolinelim@yahoo.com

Reprints will not be available from the author.

No funding support was received for this study. The authors signed disclosures that they have no proprietary or financial interest with an organization that may have a direct interest in the subject matter of this manuscript, or in any product used or cited in this study.

Presented at the Descriptive Research Contest (1st Place) Philippine Society of Otolaryngology Head and Neck Surgery, Congo Grille Restaurant, Quezon City. September 23, 2009.

\title{
Measurement of the Handicap of Dysphonic Patients using the Filipino Voice Handicap Index
}

\begin{abstract} to the different pathologies of dysphonia as determined by videostroboscopy.

\section{Methods:}

\author{
Design: Cross-sectional study. \\ Setting: Tertiary Government Hospital. \\ Population: Adult patients ( 218 years old), proficient in Filipino.
}

Objective: 1) To describe patterns of Filipino Voice Handicap Index (VHI) scores in relation to the demographic data of dysphonic patients; 2) To describe patterns of Filipino VHI scores in relation

A group of 124 dysphonic patients seen at the Videostroboscopy Unit completed the Filipino VHI. Demographic data were collected. Videostroboscopy diagnoses were classified into six groups: normal, mass lesions, inflammatory, mucosal irregularities, functional and neurogenic. The T-test was used to determine differences in scores among the demographic parameters and the pathology groups. ANOVA one-way factor was used to determine difference of subscale scores within each pathology group, and to determine difference of pathology scores in each subscale. Differences were considered statistically significant if $p<0.05$.

Results: Statistical analyses showed that Filipino VHI scores were affected by age, gender, educational status and occupation. Younger patients significantly scored higher than patients $>40$ years old. Females had significantly higher scores than males in the functional, physical and total subscales. Patients with lower educational status scored higher compared to college graduates. Voice professionals significantly scored higher than the non-voice professionals. Dysphonic patients significantly scored higher than normal volunteers. Among the pathological groups, neurogenic lesions had the highest scores. Physical subscale scores were significantly higher in all lesions except in functional lesions.

Conclusion: The Filipino $\mathrm{VHI}$ is comparable to the other versions of the $\mathrm{VHI}$, with patterns similar to other versions. It gives the clinician a measure of a dysphonic patient's handicap, and is an invaluable tool in quantifying severity of dysphonia.

Keywords: dysphonia, voice handicap index, videostroboscopy

The World Health Organization (WHO) defines handicap as the loss or limitation of opportunities to take part in community life as a consequence of a physical disorder or injury. 


\section{ORIGINAL ARTICLES}

The severity of dysphonia and how it affects a patient's daily activities are difficult to quantify. A lesion's effect may be perceived differently by a salesperson whose livelihood relies on verbal communication compared to a driver. Ultimately, the goal in the treatment of dysphonia is not only to remove the lesion, but more importantly to improve the voice. Self-evaluation then becomes an important factor in the management plan of vocal pathology. Jacobson et al. in 1997 developed the Voice Handicap Index (VHI), ' a self-administered 30-item questionnaire to measure the functional, physical and emotional impact of voice disorders. The physical subscale items included statements representing self-perceptions of laryngeal discomfort and voice output characteristics. 'Examples are "I feel as though I have to strain to produce voice" and "My voice sounds creaky and dry." Functional subscale items described the impact of a person's voice disorder on daily activities.' An example is "My voice problem causes me to lose income." Emotional subscale items consisted of statements representing patient's affective responses to voice disorders." Examples are "I feel annoyed when people ask me to repeat" and "My voice makes me feel incompetent." This psychometric tool was developed using a diverse sample of patients with voice disorders, representing the breadth of pathology in most clinical settings.

It has then been widely used to assess the effectiveness of interventions for voice disorders including voice therapy and rehabilitation, ${ }^{2,3}$ medical treatment ${ }^{4}$ and surgical procedures, ${ }^{5}$ and has been translated into several languages including German, ${ }^{6}$ Chinese, ${ }^{7,8}$ French, ${ }^{9}$ Portuguese, ${ }^{10}$ Dutch, ${ }^{11}$ Hebrew ${ }^{12}$ and Spanish. ${ }^{13}$ In 2006, a Filipino version of the VHI (Appendix B) was developed by Umali and Hernandez ${ }^{14}$ with the assistance of the Komisyon ng Wikang Filipino, Divisyon ng Pagsasalingwika (Commission of Filipino Language, Division of Translation). The Filipino version was then translated back to English and its content reviewed by a panel of laryngologists and a dyphonic patient, proficient in both Filipino and English. The final Filipino questionnaire was then tested for internal consistency on 392 primary and secondary teachers in different schools in Metro Manila. After 1 to 2 weeks, the same questionnaire was administered to the teachers to test for inter-rater reliability. The results were comparable to the original English VHI version as illustrated in Table 1.

The VHI is a subjective tool based on patients' individual perception of dysphonia. Certain patterns have been observed in the different translations. The Chinese, French, Spanish, Portuguese and Hebrew versions showed statistically significant difference between the score of dysphonic and non-dysphonic groups. The German and English versions associated severe dysphonia with largerVHI scores. The Hebrew version reported significantly higher scores for dysphonic patients

\section{Table 1. VHI versions with test-retest reliability and internal consistency results}

\begin{tabular}{l|r|r} 
Verions & Pearson's test-retest reliability (r) & $\begin{array}{c}\text { Cronbach's alpha internal } \\
\text { consistency }\end{array}$ \\
\hline English $^{1}$ & $0.7-0.79$ & 0.95 \\
\hline Filipino $^{14}$ & 0.72 & 0.8 \\
\hline German $^{6}$ & - & 0.96 \\
\hline Chinese $^{8}$ & 0.84 & 0.98 \\
\hline French $^{9}$ & 0.87 & greater then 0.7 \\
\hline Portuguese $^{10}$ & - & - \\
\hline Dutch $^{11}$ & 0.95 & 0.976 \\
\hline Hebrew $^{12}$ & $0.76-0.86$ & 0.93 \\
\hline Spanish $^{13}$ & 0.822 & \\
\hline
\end{tabular}

*Pearson's correlation: strong $r \geq 0.8$, moderate $0.5<r<0.8$, weak $r \leq 0.5$

${ }^{* *}$ Acceptable Cronbach's alpha $\geq 0.70$

with vocal pathology compared to healthy larynges, with neurogenic causes having the highest scores. The Chinese $\mathrm{VH}^{9}$ reported glottic insufficiency with significantly higher scores than functional and mass pathology.

This paper aims to 1) Describe patterns of Filipino VHI scores in relation to the demographic data (age, gender, education, occupation) of dysphonic patients seen in the Videostroboscopy Unit of the Philippine General Hospital; and 2) Describe patterns of Filipino VHI scores in relation to the different pathologies of dysphonia as determined by videostroboscopy.

\section{METHODS}

\section{Population}

The target population was dysphonic adult patients (aged 18 and above) proficient in Filipino, referred to the Videostroboscopy Unit from June 2007 to August 2009. Dysphonia was defined as any kind of perceived voice pathology.

\section{Study Setting and Design}

The study was done in the Videostroboscopy Unit of the Philippine General Hospital, Department of Otorhinolaryngology. This was a cross-sectional study using convenience sampling.

\section{Data collection}

The study protocol and informed consent were reviewed and approved by the Ethics Review Board of the institution. After acquiring individual verbal and written informed consent, 124 patients completed the Filipino VHI.

\section{Data analysis}

The Filipino VHI version of Umali and Hernandez ${ }^{14}$ used in this 
study was composed of 30 statements of experiences and reactions to voice disorders. Ten statements described the impact of a person's voice disorder on his or her daily activities (Functional subscale). Ten statements described how the patient feels about the voice disorder (Emotional subscale). Ten statements described self-perceptions of physical manifestations of dysphonia such as laryngeal discomfort and the voice pitch (Physical subscale).

Each patient related his/her agreement to the statements using a five-point Likert scale (0-never, 1- almost never, 2 - sometimes, 3 - almost always, 4 - always). The subscale score was the mean score of the 10 statements in each subscale. The severity of handicap was interpreted to be directly proportional to the numeric value assigned by the patient to each statement. The total assessment of handicap was measured by obtaining the mean of the scores on all 30 statements, the total VHI score.

Demographicdata(age, gender, educational status, occupation) were collected. Educational status included those who attained elementary (primary), high school (secondary) and college level (tertiary) education. Occupation was subdivided into professional and non-professional voice users. The professional voice users included teachers, salespeople and a choirmaster. The rest of the study population whose occupation did not depend on voice use was grouped under the non-professional voice users. These included the housewives, the unemployed, drivers, farmers and students.

Videostroboscopy diagnoses were grouped as normal; mass lesions (vocal cord cyst, nodule, polyp, leukoplakia, granuloma, mass to consider TB and carcinoma); inflammatory (laryngitis, LPR, Reinke's edema); mucosal irregularities (presbylarynx, plica ventricularis, sulcus vocalis, laryngeal web); functional (hyper/hypofunctional dysphonia, muscle tension dysphonia); neurogenic (paralysis, spasmodic dysphonia). The videostroboscopy results used in the study were interpreted by either of 2 laryngologists of the Videostroboscopy unit.

Descriptive statistics (mean and standard deviation) were used to summarize the demographic data. T-test (one-tailed) was used to determine difference between $\mathrm{VHI}$ score means in the functional, physical, emotional and total subscales among the demographic parameters and pathology groups. ANOVA one-way factor was used to determine difference of subscale scores within each pathology group, and to determine difference of pathology scores in each subscale. Differences were considered statistically significant if $p<0.05$.

\section{RESULTS}

Population. There were 124 patients who completed the Filipino VHI: 44 males (35.5\%) and 80 females (64.5\%). The mean age was 46.1years \pm 15.29 .

Filipino VHI scores and age. Patients $<40$ years old had significantly higher scores. The functional subscale score (F) was $16.88 \pm 9.26$. The physical subscale score $(P)$ was $24.49 \pm 10.04$. The emotional subscale score (E) was $15.51 \pm 9.94$. The total VHI score $(\mathrm{T})$ was $56.88 \pm 25.62$. These were higher than the values in patients $>40$ years old $(14.51 \pm 11.39 \mathrm{~F}$, $19.88 \pm 9.7 \mathrm{P}, 13.72 \pm 10.25 \mathrm{E}, 48.11 \pm 28.91 \mathrm{~T})$.

Filipino VHI scores and gender. Females $(16.25 \pm 10.55 \mathrm{~F}, 23.52 \pm 9.42$ P) scored significantly higher than males $(13.98 \pm 10.71 \mathrm{~F}, 18.39 \pm 10.44 \mathrm{P})$ only in the functional and physical subscales.

Filipino VHI scores and education. Significantly higher scores were noted in the primary and secondary group $(16.44 \pm 10.02 \mathrm{~F}, 15.76 \pm 10.16$ $E, 54.17 \pm 27.17 \mathrm{~T})$, compared to the college group $(14.81 \pm 10.98 \mathrm{~F}$, $13.03 \pm 9.91 \mathrm{E}, 49.6 \pm 28.05 \mathrm{~T}$ ) in all subscales except physical.

FilipinoVHIscores and occupation. Voice professionals (18.08 \pm 9.65 F, 25.27 \pm 7.81 P, 16.31 $\pm 9.72 E, 59.65 \pm 24.4 \mathrm{~T}$ ) showed significantly higher VHI scores in the functional, physical, emotional and total subscales than non-voice professionals $(15.14 \pm 10.95 \mathrm{~F}, 21.02 \pm 10.53 \mathrm{P}, 14.16 \pm 10.42 \mathrm{E}$, $50.33 \pm 28.83 \mathrm{~T}$ ).

Filipino VHI scores and pathology groups. Dysphonic patients $(15.57 \pm 10.56 \mathrm{~F}, 21.75 \pm 10.05 \mathrm{P}, 14.36 \pm 10.01 \mathrm{E}, 51.68 \pm 27.68 \mathrm{~T})$ significantly scored higher than non-dysphonics $(2.38 \pm 3.62 \mathrm{~F}, 1.77 \pm 3.77 \mathrm{P}, 0.23 \pm 0.44$ $E, 4.38 \pm 5.45 \mathrm{~T}$ ) on all subscales and total scores. Figure 1 presents the distribution of pathology groups, with mass lesions composing $61.3 \%$ of all lesions, followed by inflammation (14.5\%) and neurogenic lesions (12.9\%). Table 2 shows the mean scores and standard deviations of the control and the pathology groups. ANOVA results showed no significant difference among scores of the pathology groups in all subscales and the total scores ( $F p=0.09, P p=0.52, E p=0.05, T p=0.13$ ). Neurogenic lesions ranked highest among the pathologies, followed by mucosal, functional, mass and inflammatory lesions.

In each pathology group, the physical subscale (P) had the highest score compared to the functional and emotional subscales, except for functional lesions. This was significantly different only in mass and inflammatory lesions.

\section{DISCUSSION}

The Voice Handicap Index quantifies the impact of disease on patients. Through its three subscales, the clinician is able to identify the specific domain where the patient is most affected: physically, functionally and emotionally. This information guides the clinician in tailoring treatment to the needs of individual patients. Such a tool adapted to the local language is undeniably valuable.

The younger population ( $<40$ years old) had significantly higher scores than the older group. This is contrary to the observations of the 
Table 2. Average Filipino VHI scores with standard deviation of normal volunteers and pathology groups.

\begin{tabular}{l|l|lll} 
& \multicolumn{1}{|c|}{ Functional } & \multicolumn{1}{|c}{ Physical } & Emotional & \multicolumn{1}{c}{ Total } \\
Neurogenic $(n=16)$ & $21.69 \pm 9.24$ & $26 \pm 10.4$ & $21.31 \pm 9.81$ & $69 \pm 17.51$ \\
\hline Mucosal $(n=6)$ & $18.67 \pm 13.75$ & $23.83 \pm 11.87$ & $17 \pm 14.39$ & $59.5 \pm 38.56$ \\
\hline Functional $(n=5)$ & $19 \pm 8.22$ & $18.2 \pm 7.69$ & $17.6 \pm 8.79$ & $54.8 \pm 17.51$ \\
\hline Mass $(n=76)$ & $14.59 \pm 10.4$ & $21.03 \pm 9.94$ & $12.83 \pm 9.55$ & $48.45 \pm 27.23$ \\
\hline Inflammatory $(n=18)$ & $12.28 \pm 10.24$ & $21.33 \pm 10.04$ & $12.89 \pm 8.82$ & $46.5 \pm 23.7$ \\
\hline Normal $(n=3)$ & $10.33 \pm 14.57$ & $19.67 \pm 12.58$ & $17 \pm 16.64$ & $47 \pm 42.79$ \\
\hline & & & & \\
\hline Control $(n=13)$ & $2.38 \pm 3.62$ & $1.77 \pm 3.62$ & $0.23 \pm 0.44$ & $4.38 \pm 5.45$
\end{tabular}

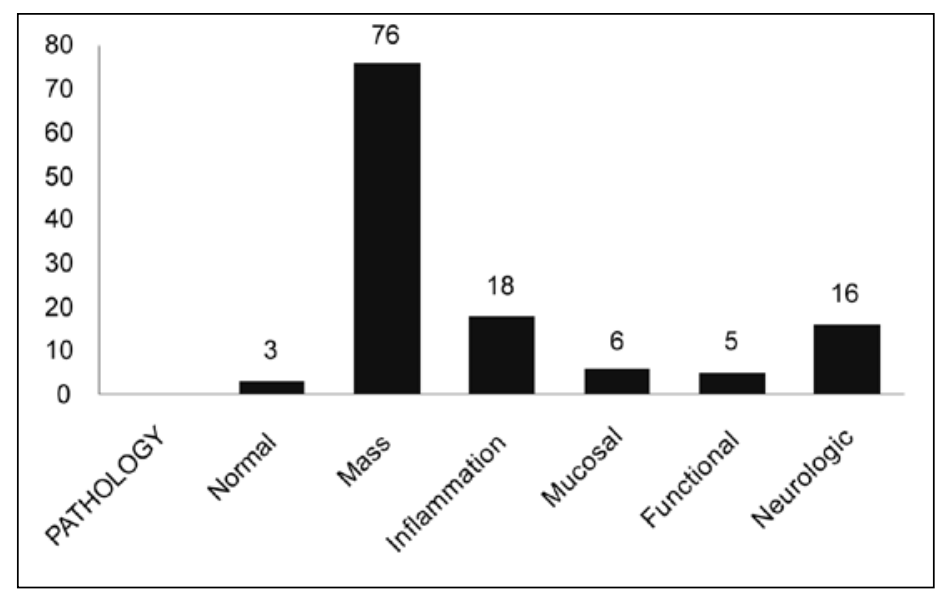

Figure 1. Distribution of pathology groups $(n=124)$.

Portuguese ${ }^{10}$ version, where the older group had higher scores, although these were not statistically relevant. The Hebrew ${ }^{12}$ version reported no significant different of scores in relation to age. Females scored significantly higher than males. In the Portuguese version, females also scored higher than males, although not statistically significant. ${ }^{10}$ Gender did not affect the scores in the Hebrew ${ }^{12}$ and Dutch ${ }^{11}$ version.

In this study, handicap was higher in young females. The younger group seemed to be more affected by dysphonia than the older population as they are more socioeconomically active. Females were more affected physically and functionally, since most had voice dependent occupations. Females and males, however, were equally affected emotionally. Voice professionals expectedly had higher handicap compared to the non-voice professionals. The group with lower educational status mostly had voice-dependent occupations, which may explain the high handicap scores.

The Filipino VHI scores were compared with the diagnoses made through videostroboscopy. According to the European Laryngological
Society, ${ }^{15}$ videostroboscopy should be included as minimal measurements in functional assessment of voice pathology and efficacy of treatment. Since other objective measurements such as acoustic analysis and aerodynamics were not available due to institutional limitations, the diagnoses to which the VHI scores were compared relied solely on the videostroboscopy findings.

Dysphonic patients significantly scored higher than non-dysphonic volunteers in all subscales. This was also reported in the Chinese, ${ }^{8}$ French, ${ }^{9}$ Spanish, ${ }^{13}$ Portuguese ${ }^{10}$ and Hebrew ${ }^{12}$ versions. This finding was consistent with the results of the English ${ }^{1}$ and German ${ }^{6}$ versions, where the severity of dysphonia was associated with higher VHI scores.

Although the scores within the pathology groups were not significant, neurogenic lesions had the highest score in all subscales significantly different from the other pathologies combined. According to Hsiung et al., glottic insufficiency due to vocal cord paralysis often manifests with a husky voice associated with choking, odynophagia and throat tightness in various levels of severity. These extralaryngeal manifestations in addition to dysphonia contribute to the severity of handicap and consequently, to the difficulty in treatment. This implies that a multidisciplinary approach is required for treatment to encompass all subscales and a thorough discussion on patient expectations of treatment is warranted.

The physical subscale $(P)$ had the highest scores compared to the functional (F) and emotional (E) subscales in all pathology groups except for functional lesions. Functional lesions in this study included hyperfunctional and hypofunctional dysphonia, as well as muscle tension dysphonia. Compared to the rest, this group's main problem is in the coordination of the vocal cord muscle movement rather than physical laryngeal abnormalities. This inefficiency of movement is often associated with learned behavior and is affected by unhealthy voice habits. Thus, treatment may be focused more on rehabilitation than on medical or surgical intervention.

Mass lesions composed $61.3 \%$ of all pathologies in this study. This group ranked fourth and scores were significantly lower in all subscales. This was contrary to the Chinese version where mass lesions scored greater than functional lesions.? Scores in the physical subscale were significantly higher than the functional and lowest in the emotional subscale. This means that the physical manifestations of dysphonia were more significant than its effect on the patient functionally and emotionally. Treatment then may be more focused on medical or surgical intervention.

Inflammatory lesions significantly scored lower than the other pathologies, except in the physical subscale. This finding is similar to the observations of the Hebrew version. ${ }^{12}$ This means that physical 
manifestations of inflammatory lesions are the most affective, thus treatment should be focused on medical intervention.

The Filipino Voice Handicap Index is comparable to the other versions of the $\mathrm{VHI}$, with patterns similar to other versions. More importantly, it gives the clinician a measure of a dysphonic patient's handicap, which is directly proportional to the score, forewarning both clinician and patient of reasonable expectations from treatment. $A$ multidisciplinary approach to the treatment of dysphonia is facilitated by the Filipino $\mathrm{VHI}$, which aids the clinician in tailoring management to focus more on the specific subscale that is most affected. High scores in the physical subscale might require medical or surgical intervention. High scores in the functional subscale might require voice rehabilitation and retraining, while high emotional scores might require counseling. It provides the clinician with a baseline measurement of the patient's handicap, which can be used to gauge the success of an intervention.

The Filipino Voice Handicap Index is an invaluable tool in quantifying severity of dysphonia in patients. A multicenter application of the Filipino VHI for all hoarse patients would provide a more comprehensive Filipino dysphonia profile. Pre- and post-treatment administration of the questionnaire could be used to assess effectiveness of several interventions.

\section{Appendix A. Voice Handicap Index Filipino version}

Instruksyon: Ito ay mga pahayag ng mga karamihan na nakaranas ng problema sa kanilang boses at kung paano ito nakaapekto sa kanilang pang-araw-araw na gawain. Bilugan lamang na sa iyong palagay na kahalintulad sa iyong mga nararamdaman.

$0=$ Hindi $1=$ Halos Hindi $2=$ Minsan $3=$ Halos Kadalasan 4= Madalas

Bahagi 1

1. Nahihirapan ang mga tao marinig ang boses ko.

2. Nahihirapan ang mga tao na maintidihan ako sa maingay na lugar.

3. Nahihirapan ang aking mga kasambahay marinig ako kapag tinatawag ko sila.

4. Dumadalang na ako gumamit ng telepono kaysa sa nais ko.

5. Umiiwas na ako sa mga tao dahil sa boses ko

6. Dumadalang na ako makipag-usap sa aking mga kamaganak, kaibigan o kapit-bahay dahil sa aking boses.

7. Ipinapaulit ng aking kausap ang aking mga sinasabi.

8. Dahil sa aking boses, nalilimitahan ang aking personal at sosyal na pamumuhay.

9. Pakiramdam ko ay hindi ako napapasama sa mga usapan. Humihina ang aking hanapbuhay dahil sa problema sa aking boses.

10. Humihina ang aking hanapbuhay dahil sa problema sa aking boses.
Bahagi II

1. Kinakapos ako ng hininga habang nagsasalita.

2. Pabago-bago ang tunog ng aking boses sa buong maghapon.

3. Nagtatanong ang mga tao, "Ano ba ang problema ng iyong boses."

4. Ang tunog ng aking boses ay minamalat at nanunuyo.

5. Pakiramdam ko ay kailangan kong bumuwelo upang makalikha ng boses.

6. Ang linaw ng aking boses ay pabago-bago/paiba-iba.

7. Sinusubukan ko na ibahin ang tunog ng aking boses.

8. Gumagamit ako ng malakas na puwersa para makapagsalita.

9. Mas masama ang aking boses kapag pagabi na.

10. Nawawalan ako ng boses sa kalagitnaan ng aking pagsasalita.

Bahagi III

1. Ninenerbiyos ako kapag nakikipag-usap sa ibang tao dahil sa aking boses.

2. Tila naiinis ang mga tao sa aking boses.

3. Pakiramdam ko ay hindi naiintindihan ng mga tao ang problema sa aking boses.

4. Ikinababahala ko ang aking problema sa boses.

5. Madalang na ako makisalamuha dahil sa aking problema sa boses.

6. Para akong may kapansanan dahil sa aking boses.

7. Naiinis ako kapag pinapaulit nila ang aking sinasabi.

8. Nahihiya ako kapag pinapaulit nila ang aking sinasabi.

9. Pakiramdam ko ay wala akong silbi dahil sa problema ng aking boses.

10. Ikinahihiya ko ang aking problema sa boses. 


\section{ACKNOWLEDGEMENT}

The authors would like to thank Ms. Michelle Mananez and Ms. Luz Agustin for their invaluable assistance in data collection and questionnaire administration.

\section{REFERENCES}

1. Jacobson BH, Johnson A, Grywalski C, Silbergleit A, Jacobson G, Benninger MS, et al. The voice handicap index (VHI): development and validation. Am J Speech Lang Pathol. 1997;6:66-70.

2. Fulljames $\mathrm{N}$, Harris $\mathrm{S}$. Voice outcome measures: correlations with patients' assessment of their condition and the effectiveness of voice therapy. Logoped Phoniatr Vocol. 2006;31(1):23-35.

3. Roy N, Gray SD, Simon M, Dove H, Corbin-Lewis K, Stemple JC. An Evaluation of the effects of two treatment approaches for teachers with voice disorders: a prospective randomized clinical trial. J Speech Lang Hear Res 2001 Apr:44(2):286-296.

4. Benninger MS, Gardner G, Grywalski C. Outcomes of Botulinum toxin treatment for patients with spasmodic dysphonia. Arch Otolaryngol Head Neck Surg. 2001 Sep;127 (9):1083-85.

5. Nuñez Batalla F, Caminero Cueva MJ, Señaris Gonzalez B, Llorente Pendas JL, Gorriz Gil C, Lopez Llames $A$, et al. Voice quality after endoscopic laser surgery and radiotherapy for early glottic cancer: objective measurements emphasizing the Voice Handicap Index. Eur Arch Otolaryngol. 2008 May;265(5):543-48

6. Nawka T, Wiesmann U, Gonnermann U. Validation of the German version of the voice handicap index. HNO. $2003 \mathrm{Nov}$;51(11):921-30. (English abstract, full article in German)

7. Hsiung MW, Lu P, Kang BH, Wang HW. Measurement and validation of the voice handicap index in voice-disordered patients in Taiwan. J Laryngol Otol. 2003 Jun;117 (6): 478-81

8. Lam PKY, Chan KM, Ho WK, Kwong E, Yiu EM, Wei WI. Cross-cultural adaptation and validation of the Chinese Voice Handicap Index-10. Laryngoscope. 2006 Jul;116 (7): 1192-8

9. Woisard V, Bodin S, Puech M. The voice handicap index: impact of the translation in French on the validation. Rev Laryngol Otol Rhinol (Bord). 2004;125(5):307-12. (English abstract, full article in French).

10. Guimaraes I, Abberton E. An investigation of the voice handicap index with speakers of Portuguese: Preliminary data. J Voice. 2004 Mar;18(1):71-82.

11. Hakkesteeg MM, Wieringa MH, Gerritsma EJ, Feenstra L. Reproducibility of the Dutch version of the voice handicap index. Folia Phoniatr Logop. 2006;58(2):132-138.

12. Amir O, Tavor Y, Leibovitzh T, Ashkenazi O, Michael O, Primov-Fever A, Wolf M. Applying the voice handicap (VHI) to dysphonic and nondysphonic Hebrew speakers. J Voice. 2006 Jun;20(2):31824.

13. Núñez-Batalla F, Corte-Santos P, Señaris-González B, Llorente-Pendás JL, Górriz-Gil C, SuárezNietoa C. Adaptation and Validation to the Spanish of the Voice Handicap Index (VHI-30) and its Shortened Version (VHI-10). Acta Otorrinolaringol Esp. 2007 Nov;58(9):386-92. (full article in Spanish and English).

14. Umali JV, Hernandez ML. Voice handicap index among Filipino teachers in primary and secondary schools in the City of Manila: reliability and preliminary validation of a questionnaire. 2006 (unpublished)

15. Dejonckere PH, Bradley $P$, Clemente $P$, Cornut $G$, Crevier-Buchman L, Friedrich $G$, et al. A basic protocol for functional assessment of voice pathology, especially for investigating the efficacy of (phonosurgical) treatments and evaluating new assessment techniques. Eur Arch Otorhinolaryngol. 2001 Feb;258(2):77-82. 